\title{
Transformation: fighting the past or building the new?
}

\section{DOI: $10.7861 /$ clinmed.ed.20.5.1}

An oft-described challenge facing physicians at this point in the COVID-19 pandemic is how to learn from the earlier phases, and what to carry forward to improve service provision. Much has been made of the importance of new technology to help bridge this transition. As we grapple with the ideas and realities of virtual consultation, it is timely to reflect and learn from one of the success stories of technology in medicine, namely in the field of diabetic management. Less invasive monitoring and improved treatment delivery through the use of emerging technologies have improved patient outcomes. The paper by Hussain and $\mathrm{Li}$ is a practical guide to the general physician who increasingly encounters patients who use these methodologies to manage their condition.?

Technological advances often come at a price - financial cost and the challenge of knowing when to use such advances. I wonder how many of us reading this have 'never' written the following radiology request: 'PUO? source of infection'. Pyrexia of unknown origin (PUO) cases, with a $3 \%$ hospital prevalence, are often complex: by definition they lack localising symptoms and signs, involve multiple systems and disciplines, and have a complex aetiology. The development of positron emission tomography / computed tomography (PET/ $\mathrm{CT}$ ) following injection of ${ }^{18} \mathrm{~F}$-fluorodeoxyglucose $\left({ }^{18} \mathrm{~F}\right.$-FDG; an agent taken up by rapidly metabolising cells) improves the accuracy and efficiency of the aetiological diagnosis of PUO. However, the investigation is expensive and identifying the optimal timing of ${ }^{18} \mathrm{~F}$-FDG PET/CT is of great practical importance. Zhu and colleagues in north-east China present a study generating data on sensitivity and specificity of early ${ }^{18} \mathrm{~F}$-FDG PET/CT in patients with PUO. ${ }^{2}$

There is methodological overlap with an interesting study by Bannaga et al from Coventry, undertaken to identify mortality predictors of hospitalised COVID-19 patients. ${ }^{3}$ While there are many such studies in the literature, this paper is an important one representing outcomes from an ethnically diverse UK city. In addition to the demographic associations, there is a simple takehome message with regard to risk stratification in the event of a future resurgence of cases. Implications for future phases of the pandemic are the subject of other manuscripts, both online and in the print edition. For example there is a pair of papers on nosocomial spread of COVID-19, with lessons on how to minimise this through twin strategies of staff hygiene and implementation of a clinical assessment tool to triage PCR (polymerase chain reaction) testing. ${ }^{4,5}$

The CME specialty in this edition is hepatology. Curated by two guest editors and our hepatology associate editor, the high-quality manuscripts make up what is essentially a mini textbook of the liver. This definitive collection of papers, on the widest range of hepatological topics, is appropriately published in the edition of Clinical Medicine immediately following the death of Prof Roger Williams. While we don't usually publish obituaries in the journal, the demise of a towering figure in their specialty is appropriately marked by Michael Glynn. ${ }^{6}$

Among the items in Clinical Medicine which provoke the greatest feedback are the lessons and images of the month and the acute medical care cases. The quality of the submissions for these is very high, and it is a pleasant struggle to narrow these down to the limited number we can publish online and in print. Simply from reading the titles of the diagnoses in these cases - pyroglutamic acidosis, methaemoglobinaemia, Wernicke's encephalopathy, remitting seronegative symmetrical synovitis - they may appear rather esoteric. $^{7-10}$ But what all these cases illustrate is the process of clinical deduction that is central to assessment and diagnosis. And whatever happens in the post-pandemic world with regard to telemedicine, these lessons - we hope - serve as a resource for study of clinical method.

\section{References}

1 Li A, Hussain S. Diabetes technologies - what the general physician needs to know. Clin Med 2020;20:469-76.

2 Zhu W, Cao W, Zheng X et al. The diagnostic value of ${ }^{18} \mathrm{~F}-\mathrm{FDG}$ PET/ $\mathrm{CT}$ in identifying the causes of fever of unknown origin. Clin Med 2020;20:449-53.

3 Bannaga AS, Tabuso M, Farrugia A. C-reactive protein and albumin association with mortality of hospitalised SARS-CoV-2 patients: A tertiary hospital experience. Clin Med 2020;20:463-8.

4 Wake RM, Morgan M, Choi J, Winn S. Reducing nosocomial transmission of COVID-19: implementation of a COVID-19 triage system. Clin Med 2020;20:e141-5.

5 Jewkes SV, Zhang YZ, Nicholl DJ. Nosocomial spread of COVID-19: lessons learned from an audit on a stroke/neurology ward in a UK district general hospital. Clin Med 2020;20:e173-7.

6 Glynn M. The life of Roger Williams. Clin Med 2020;20:488.

7 Tan YA, Ng KC, Cheo SW, Khoo TT, Low G]. A case of dapsone-induced methaemoglobinaemia. Clin Med 2020;20:519-21.

8 Trevor-Jones E, Hughes LT, Robson R, Bromley A, Stewart GW Lessons of the month: Pyroglutamic acidosis: long-term paracetamol and a high anion gap. Clin Med 2020;20:522-3.

9 Tong CV. Lessons of the month: Not just morning sickness. Clin Med 2020;20:e204-5.

10 Hassan HF, Conway R. Image of the month: Remitting seronegative symmetrical synovitis with pitting oedema (RS3PE): An important spot diagnosis. Clin Med 2020;20:524.

Anton Emmanuel Editor-in-chief

$\begin{array}{ll}\text { Members of the editorial board } \\ \text { Cono Ariti } & \text { Anton Emmanuel } \\ \text { Paul Belcher } & \text { Kate Evans } \\ \text { Rodger Charlton } & \text { Laura Ferrigan } \\ \text { Tim Chevassut } & \text { Tevfik Ismail } \\ \text { Tahseen Chowdhury } & \text { Vikas Kapil } \\ \text { Richard Corbett } & \text { Neelam Kumar } \\ \text { Elaine Dennison } & \text { Alexandra Lake } \\ \text { Albert Edwards } & \text { Yash Mahida }\end{array}$

Nick Manning-Cork Chris Marguerie Martin McKee Andrew Medford Mehool Patel Gerrard Phillips Sushma Saksena Philip Smith
Angela Star Cameron Swift Rhys Thomas Trainee associate editors: Tessa Cacciottolo Rajan Pooni Anenta Ramakrishnan 